Multi-Disciplinary meetings to ensure that the patient \& their world are kept the centre of our focus.

\section{P147 THE SOCIAL UNIVERSE - GETTING BEYOND GENOGRAMS TO MAP PATIENT NETWORKS}

Ros Taylor. Hospice of St Francis, Berkhamsted, United Kingdom

\subsection{6/bmjspcare-2013-000591.169}

Context Forecasts of profound demographic change and diminishing health care resources together with patient preferences to be cared for at home, suggest that future community support will need to be shaped very differently, identifying new sources of resilience.

Networks around people could be harnessed to offer social and practical support, and in many cases healthcare support. This underpins the public health approach to palliative care.

Proposal There is a presumption by practitioners that the traditional genogram describes the support network - this may be the case but it seems important to understand a more inclusive and interactive network, the strength and weakness of the links, potential for change and the conversations needed to facilitate strengthening of these links. Network 'poor' patients will also be identified.

The Social Universe Tool (based on Macy's support map)

The palliative patient is given a blank sheet with their name in the centre and is asked to map all those people in their 'universe'.

These may include :

Relatives, friends and neighbours

Facebook friends

Work colleagues

Members of groups or clubs

The thickness of arrows drawn in both directions between the patient and each name determines the strength of support given and received.

Reflections on conversations that need to happen to strengthen key relationships are formulated together

For example - there may be a thin line from a friend towards the patient - the patient feels this friend would like to help more - what conversation needs to happen to strengthen the universe ?

Initial results The Social Universe map has been piloted to look at acceptability and usability with 20 patients of different ages and backgrounds.

All patients have found it a creative and relevant way to understand their networks and to think about tactics to strengthen relationships!

Next Steps Formal evaluation with professionals and patients, followed by training of hospice practitioners to launch as part of routine holistic assessment.

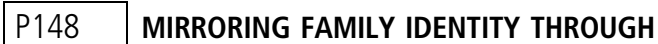 DOCUMENTARY FILMMAKING: INNOVATIVE WAYS OF WORKING WITH FAMILIES IN A HOSPICE SETTING.}

Haraldsdottir Erna, Amy Hardie Kendall Maril. Strathcarron Hospice, Denny, Stirlingshire, Primary Palliative Care Research Group, The University of Edinburgh

\subsection{6/bmjspcare-2013-000591.170}

Background Expressive arts are increasingly being used within Palliative Care (PC) to add to desired outcomes. We wished to develop these techniques working with families in a hospice setting.

Aims To explore \& evaluate the use of documentary film making techniques in PC to support families and patients.

Method A film artist, resident in a hospice for a year, worked with staff, patients \& families using \& teaching camera $\&$ editing skills to produce documentary films. They took part in a series of qualitative interviews to explore their experience. 30 interviews were completed, transcribed verbatim \& entered into Nvivo 7 for thematic analysis.

Results 12 families made films in an iterative process that included reflective listening $\&$ screening, which this paper will analyse as 'mirroring'. These films had various purposes such as 'legacies', made for those facing bereavement, 'portraits' allowing the family to see \& take stock of their life stories; 'play spaces', where family members could express the parts of themselves that may get submerged in the problem-solving ethos of dealing with illness.

Conclusion The families found making a documentary film about their life brought them together, allowing them to 'tell their story' \& leave a legacy of family archive. Patients reported they enjoyed specifically seeing the closeness between the family members \& the positive functioning of the family reflected in the film. The legacy aspect of the film is of particular importance to patients with young children. Documentary film goes further than the traditional 'memory box', it captures the day-today life of the family together reflecting the relationship the patient has with his/her family as well as mirroring the family identity. Working with a film artist in a hospice has equipped the staff with new technical knowledge \& a ground-breaking documentary intervention to use with families in a PC setting.

Funding : Creative Scotland

\section{P149 DISCOURSE ON METHOD: TESTING A METHODOLOGY FOR USE IN UNDERSTANDING WHAT SPIRITUAL CARE SPECIALISTS MEAN BY 'SPIRITUAL NEED'}

Steve Nolan. Princess Alice Hospice, Esher, UK

10.1136/bmjspcare-2013-000591.171

Aim To test a methodology for use in understanding what is meant by 'spiritual need'

Background Nurses are required routinely to conduct spiritual assessments (NMC 2010). Yet, despite a growing literature around spiritual assessment (McSherry \& Ross 2010; Holloway et al 2011), knowledge about what constitutes spiritual needs remains limited. Without this knowledge, nurses are ill-equipped to make their assessments (McSherry \& Jamieson 2011). The methodology is intended to be used in a lager study aimed at building a spiritual need typology.

Method The pilot study - an interpretive study using a form of discourse analysis - worked with 9 spiritual care specialists, each of whom shared, in depth, one encounter with a person they considered had been in 'spiritual need'. Working in focus groups and using semi-structured questions, the method aimed to:

1. gather narrative accounts about the experience of people in spiritual need;

2. generate descriptive vocabulary articulating those experiences.

Participants orally described their encounter, which they then documented on a specially designed form. Participants next 